nhóm chuyển 2 phôi. Nhóm chuyển 3 phôi có beta hCG sau chuyển phôi, tỷ lệ có thai lâm sàng, tỷ lệ đa thai, tỷ lệ sinh non, tỷ lệ thai lưu cao hơn nhóm chuyển 2 phôi. Không có sự khác biệt về tỷ lệ thai sinh sống giữa 2 nhóm chuyển 2 và 3 phôi. Chuyển 3 phôi làm tăng gấp 3,24 lần nguy cơ đa thai, gấp 2 lần nguy cơ đẻ non so với chuyển 2 phôi. Chuyển 2 phôi là lựa chọn hợp lý, an toàn và hiệu quả.

\section{TÀI LIẸU THAM KHẢO}

1. International Federation of Fertility Societies' Surveillance (IFFS) 2019: Global Trends in Reproductive Policy and Practice, 8th Edition. Global Reproductive Health. 2019;4(1):e29-e29

2. Masschaele T, Gerris J, Vandekerckhove F, De Sutter P. Does transferring three or more embryos make sense for a well-defined population of infertility patients undergoing IVF/ICSI? Facts Views Vis Obgyn. 2012;4(1):51-58

3. Ashrafi $M$, Madani $T$, Movahedi $M$, et al. Increasing The Number of Embryos Transferred from Two to Three, Does not Increase Pregnancy
Rates in Good Prognosis Patients. International journal of fertility \& sterility. 2015;9:292-299.

4. Martikainen $H$, Group the FES, Titinen A, et al. One versus two embryo transfer after IVF and ICSI: a randomized study. Hum Reprod. 2001;16(9):1900-1903.

5. Vương Thị Ngoc Lan. Giá trị các xét nghiêm $\mathrm{AMH}, \mathrm{FSH}$ và $\mathrm{AFC}$ dự đoán đáp ứng buồng trứng thụ tinh trong ống nghiệm. Đại học $Y$ dược thành phố Hồ Chí Minh.2016.

6. Sunkara SK, Rittenberg $\mathbf{V}$, Raine-Fenning $\mathbf{N}$, Bhattacharya S, Zamora J, Coomarasamy A. Association between the number of eggs and live birth in IVF treatment: an analysis of 400135 treatment cycles. Hum Reprod. 2011;26(7):1768-1774.

7. Taşdemir M, Taşdemir I, Kodama H, Fukuda J, Tanaka T. Implantation: Two instead of three embryo transfer in in-vitro fertilization. Hum Reprod. 1995; 10(8):2155-2158.

8. Min JK, Hughes E, Young D, Joint Sogc-Cfas Clinical Practice Guidelines Committee, Reproductive Endocrinology And Infertility Committee. Elective single embryo transfer following in vitro fertilization. J Obstet Gynaecol Can. 2010;32(4):363-377.

\title{
ĐÁNH GIÁ HIỆU QUẢ ĐIỀU TRI GIẢM ĐAU BÊNNH NHÂN UNG THƯ DI CĂN XƯO'NG BẰNG XẠ TRI TẠI BỆNH VIỆn 198-Bộ CÔNG AN
}

\section{Nguyễn Thị Minh Phương*, Hoàng Thanh Tuyền*, Nguyễn Minh Dũng*, Vi Thành Long*}

\section{TÓM TẮT}

30 bênh nhân ung thư di căn xương đau mức độ vừa hoặc nặng, được điều trị bằng thuốc giảm đau thông thường không hiệu quả. Chiếu xạ ngoài đạt hiêu quả giảm đau sau 1 tuần, giảm đau tốt sau 1 tháng, $20 \%$ hết đau hoàn toàn, $70 \%$ đáp ứng một phân, 10\% bênh không đáp ứng giảm đau. Giảm đau sau xạ trị có ý nghĩa thống kê ở tất cả các nhóm 1 vị trí tổn thương, > 1 vị trí tổn thương và có tổn thương kết hơp.

Từ khóa: Ung thư di căn xương, giảm đau, xạ trị

\section{SUMMARY}

\section{EFFECTS OF PALLIATIVE TREATMENT BY RADIATION IN CANCER PATIENTS WITH BONE METASTASES AT 198 HOSPITAL}

30 patients with pain (moderate or severe) due to bone metastase were treated by conventional analgesics drug but not effective. These patients were treated by radiation bone pain relief response last 1 week good response last 1 month, 20\% very good

*Bệnh viện 198, Bộ Công An

Chịu trách nhiệm chính: Nguyễn Thị Minh Phương

Email: drminhphuong198@gmail.com

Ngày nhận bài: 26/12/2021

Ngày phản biện khoa học: 28/1/2021

Ngày duyệt bài: 26/2/2021 response, $70 \%$ with partial response, $10 \%$ not response. Bone pain relief response in all group 1 tumor, $>1$ tumors and many tumors.

Keywords; Bone cancer, analgesics, radiation

\section{I. ĐĂT VẤN ĐỀ}

Ung thư có su hướng ngày càng gia tăng trong những thập niên gần đây, bệnh nhiều khi không có triệu chứng lâm sàng rõ rệt. Bệnh thường phát hiện khi đã ở giai đoạn muộn, có di căn xa. Tỷ lệ ung thư di căn xương chiếm từ 30$70 \%$ số bệnh nhân tùy theo loại ung thư và giai đoan bênh [5]. Ung thư di căn xương không những làm giảm thời gian sống của bênh nhân mà còn giảm chất lượng sống và gây các triệu chứng thường gặp như đau xương (xảy ra ở 2/3 bênh nhân có di căn xương). Điều trị giảm đau có vai trò quan trọng và cần thiết, nhằm cải thiện chất lượng sống cho người bệnh. Có nhiều phương pháp điêu trị giảm đau như: phẫu thuật, hóa trị, thuốc giảm đau, xạ trị...Mỗi phương pháp có tác dụng trong những trường hợp nhất định. Sử dụng thuốc giảm đau có tác dụng trong thời gian ngắn, nhiều tác dụng phụ khồng mong muốn, tình trạng nhờn thuốc khiến bênh nhân phải tăng liều... Điều trị giảm đau bằng xạ trị 
được chứng minh có hiệu quả, giảm đau nhanh sau 3-4 ngày và kéo dài 3-4 tháng, 30-60\% giảm đau hoàn toàn [3],[4]. Đề tài này chúng tôi nghiên cứu với mục tiêu đánh giá hiệu quả giảm đau bệnh nhân ung thư di căn xương bằng phương pháp xạ trị.

\section{II. ĐỐI TƯợNG VÀ PHƯƠ'NG PHÁP NGHIÊN CỨU \\ 2.1. Đối tượng}

- Tiêu chuẩn lựa chọn. Gồm 30 bệnh nhân $\geq 18$ tuổi được chẩn đoán xác định ung thư bằng giải phẫu bệnh có di căn xương và có triệu chứng đau (mức độ vừa hoặc nặng) do ung thư di căn gây ra (10 bênh nhân ung thư phổi, 5 bệnh nhân ung thư vú, 5 bệnh nhân ung thư gan mật, 8 bệnh nhân ung thư đại tràng, 2 bệnh nhân ung thư tuyến tiền liệt). Bệnh nhân được chụp xạ hình xương dương tính ở các vị trí phù hợp với đau trên lâm sàng (1-2 ổ), dùng thuốc giảm đau thông thường không đỡ, bệnh nhân chấp nhận điều trị bằng tia xạ.

- Tiêu chuẩn loại trừ

- Ung thư xương nguyên phát, đang điều trị bằng các biện pháp toàn thân (hóa chất, nội tiết), ý thức kém, không tự nhận xét được tình trạng chủ quan của minh, dị ứng với tia xạiên lượng sống dưới 3 tháng.

2.2. Phương pháp: Nghiên cứu tiến cứu, theo dõi doc

\subsection{Các bước tiến hành}

2.3.1. Đánh giá trước điêu trị và sau điêu trị

- Lâm sàng: Đánh giá triệu chứng đau trước và sau xa 1 tuần, 2 tuần, 1 tháng, 2 tháng theo thang điểm bằng thước đo thị số VAS

- Cận lâm sàng trước xạ trị: Mô bệnh học chẩn đoán ung thư, xạ hình xương chẩn đoán di căn xương.

\subsubsection{Các bước tiến hành xạ trị}

- Bước 1. Chuẩn bị bệnh nhân.

- Bước 2. Cố định bệnh nhân

- Bước 3. Chụp CT mô phỏng

- Bước 4. Lập kế hoạch xạ trị

- Bước 5. Tiến hành xạ trị

\subsection{Phân tích và xử lý số liêu:}

- Các thông tin thu thập được mã hoá và xử lý trên phần mềm SPSS 16.0.

- Các thuật toán thống kê:

+ Mô tả: trung bình, độ lệch chuẩn, giá trị max, min.
+ Kiểm định so sánh:

\section{KẾT QUẢ NGHIÊN CỨU}

Trước điều trị tất cả các bệnh nhân đều đau, trong đó đau nặng 11 bệnh nhân $(36,7 \%)$, đau vừa 19 bệnh nhân (63,3\%). Bệnh nhân được điều trị giảm đau bằng chiếu xạ ngoài.

Bảng 1. Hiệu quả giảm đau của chiếu xạ ngoài Đáp ứng điều trị Số bệnh nhân Tỷ lệ \%

\begin{tabular}{|c|c|c|}
\hline Hết đau hoàn toàn & 6 & 20 \\
\hline Đáp ứng một phần & 21 & 70 \\
\hline Đau không thay đối & 3 & 10 \\
\hline Tống & 30 & 100 \\
\hline
\end{tabular}

Nhận xét: Sau điêu trị có $20 \%$ bệnh nhân hết đau hoàn toàn, $70 \%$ bệnh nhân đõ đau (đáp ứng một phần), 10\% bệnh nhân đau không thay đổi. Trong 27 bệnh nhân đáp ứng giảm đau, thời gian bắt đầu có hiệu quả sớm nhất sau 3 ngày, chậm nhất sau 1 tuần.

Bảng 2. Điểm đau của bệnh nhân trước và sau xa tri

\begin{tabular}{|c|c|c|}
\hline Thời điểm & $\begin{array}{c}\text { Điểm đau } \\
\text { trung bình }\end{array}$ & P \\
\hline Trước xạ trị (T0) & $7,13 \pm 1,50$ & \\
\hline Sau 1 tuần (T1) & $5,67 \pm 2,27$ & PT0-PT1<0,01 \\
\hline Sau 2 tuần (T2) & $3,73 \pm 2,46$ & PT0-PT2 $<0,01$ \\
\hline Sau 1 tháng (T3) & $3,43 \pm 2,66$ & PT0-PT3 $<0,01$ \\
\hline Sau 2 tháng (T4) & $3,40 \pm 2,50$ & PT0-PT4 <0,01 \\
\hline
\end{tabular}

Nhân xét: Tác dụng giảm đau có ý nghĩa thống kê sau 1 tuần xạ trị, sau 2 tuần xạ trị có 1 bệnh nhân hết đau hoàn toàn, sau 1 tháng xạ trị có 6 bênh nhân hết đau hoàn toàn.

Bảng 4. Hiệu quả giảm đau theo số vị trí di căn xương

\begin{tabular}{|c|c|c|c|}
\hline Vị trí & $\begin{array}{c}\text { Điểm đau } \\
\text { trung bình } \\
\text { trước xạ trị }\end{array}$ & $\begin{array}{c}\text { Điếm đau } \\
\text { trung bình } \\
\text { sau xá trị 1 } \\
\text { tháng }\end{array}$ & $\mathbf{P}$ \\
\hline $\begin{array}{c}1 \text { vị trí } \\
(\mathrm{n}=14)\end{array}$ & $6,43 \pm 1,39$ & $1,64 \pm 1,78$ & $<0,01$ \\
\hline $\begin{array}{c}>1 \text { vị trí } \\
(\mathrm{n}=10)\end{array}$ & $7,70 \pm 1,49$ & $4,30 \pm 2,11$ & $<0,01$ \\
\hline $\begin{array}{c}\text { Kết hợp di } \\
\text { căn khác } \\
(\mathrm{n}=6)\end{array}$ & $7,83 \pm 1,17$ & $6,17 \pm 2,31$ & $<0,05$ \\
\hline
\end{tabular}

Nhân xét: Điểm đau trung bình sau xa 1 tháng ở các nhóm 1 vị trí, >1 vị trí, có tổn thương kết hợp đều giảm có ý nghĩa thống kê so với trước xạ. Ở nhóm 1 vị trí tổn thương giảm rõ rệt hơn, sự khác biệt có ý nghĩa thống kê $p<0,01$.

Bảng 3. Giảm mức độ đau ở các thời điểm sau xạ trị

\begin{tabular}{|c|c|c|c|c|c|c|}
\hline \multirow{2}{*}{ Mức độ đau } & \multicolumn{2}{|c|}{ Trước điêu trị } & \multicolumn{2}{c|}{ Sau 1 tháng } & \multicolumn{2}{c|}{ Sau 2 tháng } \\
\cline { 2 - 7 } & $\mathbf{n}$ & $\mathbf{\%}$ & $\mathbf{n}$ & $\mathbf{\%}$ & $\mathbf{n}$ & $\mathbf{\%}$ \\
\hline Đau nặng (8-10 điếm) & 11 & 36,7 & 3 & 10 & 3 & 10 \\
\hline
\end{tabular}




\begin{tabular}{|c|c|c|c|c|c|c|}
\hline Đau vừa (5-7 điếm) & 19 & 63,3 & 6 & 20 & 5 & 16,7 \\
\hline Đau nhẹ (1-4 điếm) & 0 & 0 & 15 & 50 & 16 & 53,3 \\
\hline Khống đau & 0 & 0 & 6 & 20 & 6 & 20 \\
\hline
\end{tabular}

Nhận xét: Sau 1 tháng hiệu quả giảm đau đạt tốt chỉ con 3 bệnh nhân đau nặng, phần lớn bệnh nhân còn đau nhẹ, cải thiện rỗ rệt so với trước điều trị. Sau 2 tháng theo dõi đáp ứng giảm đau vẫn giữ được ổn định.

\section{BÀN LUÂN}

Qua nghiên cứu 30 bệnh nhân ung thư di căn xương được điều trị bằng phương pháp xạ trị. Kết quả cho thấy hiệu quả giảm đau cho nhiều trường hợp và là lựa chọn hợp lý cho bệnh nhân đáp ứng kém với thuốc giảm đau thông thường, thể trạng yễu không điều trị được phẫu thuật hoặc hóa chất. Trước điều trị nhóm nghiên cứu của chúng tôi tất cả bệnh nhân có triệu chứng đau từ nặng đến vừa $36,7 \%$ đau mức độ nặng, $63,3 \%$ đau mức độ vừa. Kết quả sau một tuần mức độ đau đã giảm, sau 1 tháng mức độ đau giảm tốt chỉ còn $10 \%$ bệnh nhân đau mức độ nặng, có $20 \%$ bệnh nhân hết đau hoàn toàn, $70 \%$ bệnh nhân đáp ứng một phần. Tác giá Gaze M.N, Kelly C.G và cộng sự [2] tổng kết giảm đau sau xạ trị cho bệnh nhân ung thư di căn xương tỷ lệ đáp ứng từ $83,7-89,2 \%$, giảm đau hoàn toàn từ $38,8-42,3 \%$, giảm đau nhanh sau 3-4 ngày xa trị. Tác giả đoàn lực đã xạ trị cho 87 bệnh nhẩn ung thư di căn xương kết quả giảm đau từ ngày thứ 5 và giảm đau tốt từ ngày thứ 31. Điểm đau trong nghiên cứu của chúng tôi trước điều trị 7,13 $\pm 1,50$ điểm, giảm dần sau 1 tuần, 2 tuần, 1 tháng, 2 tháng tương ứng là $5,67 \pm 2,27,3,73 \pm 2,46,3,43 \pm 2,66,3,40 \pm 2,50$, sự khác biệt có ý nghĩa thống kê $p<0,01-0,05$. Phù hợp với kết quả của tác giả Đoàn Lực [1]. Hiệu quả giảm đau xa xạ trị có ý nghĩa ở tất cả các nhóm 1 vị trí tổn thương, > 1 vị trí tổn thương và có tổn thương phối hợp.

\section{KẾT LUÂ̂N}

- Hiệu quả giảm đau sau 1 tuần xạ trị, giảm đau tốt sau 1 tháng xa trị

- Điểm đau giảm có ý nghĩa thống kê so sánh trước và sau xạ 1 tuần, 2 tuần, 1 tháng, 2 tháng.

- Sau xa trị có $20 \%$ bênh nhân hết đau hoàn toàn, $70 \%$ đáp ứng một phẩn, $10 \%$ đau không giảm.

- Sau xạ trị 1 tháng điểm đau giảm ở tất cả các nhóm ung thư di căn xương 1 vị trí, > 1 vị trí và nhóm có tổn thương kết hợp.

Từ những kết quả thu được, cho thấy xạ trị chiếu ngoài điều trị giảm đau cho bệnh nhân ung thư di căn xương là một phương pháp hiệu quả.

\section{TÀI LIẸU THAM KHẢO}

1. Đoàn Lực (2012) Đánh giá hiệu quả điều trị di căn xương bằng tia xa ngoài, zoledronic acid và thuốc giảm đau, Luận án tiến sĩ Y học, Hà nội

2. Gaze M.N, Kylly C.G et al (1997) "Pain relief and quality of life following radiotherapy for bone metastases: a randomised trial of two fraction schedules", Radiother Oncol, Vol 42, No 2, 16-109.

3. Nguyễn Hữu Thợi (2007), Các nguyên tắc xạ trị trong ung thư. Chẩn đoán và điều trị bệnh ung thư. Nhà xuất bản y học. 2007. tr.31-38.

4. Lutz S (2011), Palliative Radiotherapy for Bone Metastases: an ASTRO Evidence - Based Guideline. International Journal of Radiation Oncology * Biology * Physics. Volume 79, Issue 4 p965 - 76. 15 March 2011.

5. Mueller A et al (2001), On metastasis in cancer. Nature 2001 410:50

\section{ĐÁNH GIÁ CHẤT LƯỢNG DİCH VỤ KHÁM CHŨ̃A BÊNH NGOẠI TRÚ TẠI BÊ̂NH VIÊ̂N TRUNG ƯO'NG QUÂN ĐộI 108}

\section{Lê Thị Thu Hải*, Bàn Nguyễn Thị Hằng*, Vũ Hồng Vân*}

TÓM TẮT

Mục tiêu: Đánh giá các yễu tỗ ảnh hưởng đễn chất lượng dịch vụ (CLDV) khám, chữa bệnh qua cảm nhận của người đển khám, chứa bệnh ngoại trú tại

*Bênh viên Trung ương Quân đội 108

Chịu trách nhiệm chính: Lê Thị Thu Hải

Email: Lethuhai3009@gmail.com

Ngày nhận bài: 5/1/2021

Ngày phản biên khoa học: 1/2/2021

Ngày duyệt bài: 26/2/2021
Bênh viện Trung ương Quân đôi 108 (BV). Đối tượng và phương pháp: Nghiên cứu định lượng sử dụng công cụ phỏng vấn SERVPERF cho 600 người đến khám, chữa bệnh ngoai trú tai khu Phẫu thuất thẩm mỹ- laser công nghệ cao, bệnh viện Trung ương Quân đội 108. Kết quả và kết luân: Điểm trung bình (TB) CLDV chung là 4,23 $\pm 0,26$ điểm, trong đó 5 khía cạnh CLDV đat tữ 4,15 đến 4,39 điểm. Nhóm yếu tố quyết định chất lượng dịch vụ được đánh giá cao nhất là yếu tổ hữu hình, nhóm yếu tố có điểm thấp nhất là yếu tố cảm thông chia sẻ. CLDV tại khu Phẫu thuật thẩm mỹlaser công nghệ cao, khoa Phẫu thuật theo yêu câu, 